\title{
SEXO E SEXUALIDADE: tabu, polêmica ou conceitos polissêmicos? Reflexões sobre/para a formação de educadores
}

\author{
Elizabeth Antônia Leonel de Moraes Martines' \\ Juliana Negrello Rossarolla ${ }^{2}$
}

\section{RESUMO}

Este trabalho tem como objetivo realizar uma "reflexão sobre a ação e sobre a reflexão-na-ação" a partir de dois encontros de uma pesquisa-ação colaborativa (IBIAPINA, 2008) sobre e para a formação de educadores sexuais para atuarem na Educação Básica, a qual aliou a formação-investigação de uma mestranda com o processo de formação inicial em uma Licenciatura em Ciências Biológicas de um Instituto Federal amazônico. Os encontros desta pesquisadora com os estudantes (colaboradores) consistiram em ações diagnósticas, estudos de textos e diálogos sobre a questão "O que é sexo e sexualidade? Você se sente preparado para atuar em educação sexual?". O registro dos dados foi realizado em planejamentos dos encontros, videogravação da interação e registro ampliado realizado nas vinte e quatro horas subsequentes. Os vídeos foram analisados novamente alguns meses depois para reflexão mais aprofundada com a análise do discurso, de acordo com referencial de Schön (1992) e Foucault (1999). Constatou-se que a temática é complexa, não aparece no Projeto Pedagógico do Curso, mas os alunos vivenciaram várias atividades na prática formativa, especialmente no PIBID, por iniciativa de alguns professores-formadores, mas as mesmas foram consideradas insuficientes. Concluiu-se com a convicção de que os professores necessitam de uma formação permanente e de trabalho coletivo na escola (especialmente através da pesquisa-ação colaborativa) para exercerem com responsabilidade e compromisso social a tarefa de educadores sexuais.

Palavras-chave: Educação Sexual. Formação de Professores. Pesquisa-ação Colaborativa.

\footnotetext{
1 Professora aposentada no Departamento de Biologia da Universidade Deferal de Rondônia (UNIR), Licenciada em Ciências Biológicas; Mestrado e Doutorado em Psicologia Escolar e do Desenvolvimento Humano (IP/USP). Orientadora no Mestrado Profissional de Educação Escolar (MEPE / UNIR), no Mestrado de Psicologia (MAPSI / UNIR) e Doutorado em Educação em Ciências e Matemática (PPEGECEM) da Rede Amazônica de Educação em Ciências e Matemática (REAMEC). E-mail: bethmartines@gmail.com

2 Técnica em Assuntos Educacionais no Instituto Federal de Ciência e Tecnologia de Rondônia (IFRO), lotada no Campus de Colorado do Oeste. Licenciada em Letras, Especialização em Psicopedagogia, Mestrado Profissional em Educação Escolar pela Universidade Federal de Rondônia (UNIR). E-mail: juliana.rossarolla@ifro.edu.br
} 


\title{
SEX AND SEXUALITY: taboo, controversy or polysemic concepts? Reflections
}

\author{
on / for the preparation of educators
}

\begin{abstract}
This work aims to carry out a "reflection on action and on reflection-in-action" based on two meetings of a collaborative action research (IBIAPINA, 2008) on and for the formation of sexual educators to work in Basic Education, which allied the education-research of a master's student with the initial teacher education process in a Teaching Licensure in Biological Sciences of an Amazonian Federal Institute. The meetings of this researcher with the students (collaborators) consisted in diagnostic actions, text studies and dialogues on the question "What is sex and sexuality? Do you feel prepared to engage in sex education?". Data recording was performed in meeting planning, video recording of the interactions and extended recording in the subsequent twenty-four hours. The videos were analyzed again a few months later for more in-depth reflection with discourse analysis, according to Schön (1992) and Foucault (1999). It was found that the theme is complex, it does not appear in the Pedagogical Project of the Course, but the students experienced several activities in the formative practice, especially in the PIBID, at the initiative of some teacher educators, but these were considered insufficient. It was concluded with the conviction that teachers need ongoing formation and collective work in school (especially through collaborative action research) to exercise with responsibility and social commitment the task of sexual educators.
\end{abstract}

Keywords: Sexual Education. Teacher education. Collaborative action research.

\section{SEXO Y SEXUALIDAD: tabu, polémica o conceptos polisémicos?}

\section{Reflexiones sobre / para la formación de educadores}

\section{RESUMEN}

Este trabajo tiene como objetivo realizar una "reflexión sobre la acción y sobre la reflexión en la acción" a partir de dos encuentros de una investigación-acción colaborativa (IBIAPINA, 2008) sobre y para la formación de educadores sexuales para actuar en la Educación Básica, la cual recuperó la formación-investigación de una maestreanda con el proceso de formación inicial en una Licenciatura en Ciencias Biológicas de un Instituto Federal amazónico. Los encuentros de esta investigadora con los estudiantes (colaboradores) consistieron en acciones diagnósticas, estudios de textos y diálogos sobre la cuestión "¿Qué es el sexo y la sexualidad? ¿Se siente preparado para actuar en educación sexual?". El registro de los datos fue realizado en planificaciones de los encuentros, videograbación de la interacción y registro ampliado realizado en las veinticuatro horas subsiguientes. Los vídeos fueron analizados nuevamente unos meses después para una reflexión más profunda con el análisis del discurso, de acuerdo con referencial de Schön (1992) y Foucault (1999). Se constató que la temática es compleja, no aparece en el Proyecto Pedagógico del Curso, pero los alumnos vivenciaron varias actividades en 
la práctica formativa, especialmente en el PIBID, por iniciativa de algunos profesores-formadores, pero las mismas fueron consideradas insuficientes. Se concluyó con la convicción de que los profesores necesitan una formación permanente y de trabajo colectivo en la escuela (especialmente a través de la investigación-acción colaborativa) para ejercer con responsabilidad y compromiso social la tarea de educadores sexuales.

Palabras clave: Educación Sexual. Formación de profesores. Investigación-acción colaborativa.

\section{INTRODUÇÃO}

Este trabalho foi escrito a "quatro mãos", como se costuma dizer nas apresentações artísticas em piano, em que a mesma música é tocada por dois artistas ao mesmo tempo no mesmo piano, os quais precisam coordenar suas execuções tocando em teclas diferentes para obter sons que se complementam para compor uma melodia harmoniosa. É considerado um bom recurso didático, pois geralmente possui uma parte mais difícil e elaborada a ser tocada por um profissional mais experiente e outra parte menos elaborada para pianistas menos experientes, cuja composição final enriquece a ambos os músicos e o resultado auditivo é muito agradável aos que ouvem a execução. Assim, neste trabalho, apresentamos resultados parciais de uma pesquisa com o objetivo de realizar uma "reflexão sobre a ação e sobre a reflexão-na-ação" desenvolvidas nos dois primeiros encontros de uma pesquisa-ação colaborativa (IBIAPINA, 2008), a qual aliou a investigação de uma mestranda com o processo de formação de professores para atuarem em Educação Sexual na Educação Básica. Os encontros são resultados da colaboração entre a mestranda, sua orientadora e doze estudantes de uma Licenciatura de Ciências Biológicas de um Instituto Federal de Ciência e Tecnologia situado na Amazônia. Consistiram em ações diagnósticas, estudos de textos e diálogos sobre as questões: "O que é sexo e sexualidade? Vocês receberam formação e se sentem preparados para atuarem como educadores sexuais?". A discussão destas questões gerou reflexão sobre a formação e a prática docente as quais aprofundamos neste trabalho relacionando autores utilizados nos 
encontros de estudo com outros autores consagrados sobre a temática, o que resultou em aprendizagem para ambas as pesquisadoras envolvidas.

O texto está dividido em quatro seções: na Seção 2, apresentamos a ação (dois encontros de investigação-formação) e o referencial teóricometodológico utilizado; na Seção 3 descrevemos as ações com destaque para os diálogos e reflexões ocorridas (reflexão-na-ação). Na Seção 4, buscamos o nível mais elevado de reflexão proposto por Schön, ou seja, fazemos uma reflexão sobre a ação e sobre a reflexão-na-ação na discussão dos dados relacionando-os com autores consagrados na área.

\section{A PESQUISA E SEU REFERENCIAL TEÓRICO-METODOLÓGICO}

Esta pesquisa se dá na abordagem qualitativa e, de acordo com Pereira podemos concluir que se pode defini-la como uma pesquisa-ação por tratar-se do "estudo de uma situação social para tratar de melhorar a qualidade da ação que nela intervém" (1998, p. 166). O que diferencia essa pesquisa de outras é o papel fundamental que ela proporciona na transformação de uma dada realidade social, já que busca resolver de forma democrática uma problemática encontrada na realidade dos participantes. Essa problemática é o ponto de partida de toda pesquisaação e entre diferentes modelos desta modalidade de pesquisa (pesquisa participante, pesquisa-ação existencial, investigação-formação, pesquisa colaborativa, entre outras), adotamos a proposta de pesquisa-ação colaborativa defendida por Ibiapina (2008), a qual envolve professores e investigadores num processo de produção de saberes e troca de experiências com o objetivo de resolver problemas educacionais em comum, com ênfase na formação das pessoas envolvidas.

É uma proposta de investigar em colaboração, onde há um envolvimento entre todos participantes, com diferentes papéis no desenrolar da pesquisa, mas que minimiza a dicotomia teoria-prática e a rígida hierarquia entre pesquisadores universitários e professores da educação básica. "A pesquisa colaborativa surge no ambiente da educação como alternativa para 0 desenvolvimento de estudos considerados 
emancipatórios" (IBIAPINA, 2008, p. 25), contribuindo assim, "[...] com a disseminação de atitudes que motivam a coprodução de conhecimentos voltados para a mudança da cultura escolar e para o desenvolvimento profissional dos professores." (p. 23).

O registro dos encontros, dos diálogos e de muitas reflexões se deu com a escrita de planejamentos dos encontros, a gravação em vídeos das interações com os colaboradores, os quais permitiram a criação de registros ampliados pela pesquisadora iniciante logo após a realização das atividades (ROCKWELL, 1987). Entre outros procedimentos metodológicos de investigação e formação que Ibiapina sugere, encontram-se as narrativas, relato oral de vida ou relato autobiográfico e buscamos usá-las em nossos encontros chamando-as de "experiências vivenciadas".

Assim, neste trabalho, durante a investigação realizada por uma mestranda (pesquisadora iniciante ou PI) com um grupo de acadêmicos de Biologia (colaboradores ou C), sob a orientação de uma pesquisadora mais experiente (orientadora ou O) se investiu em um processo de formação docente, numa perspectiva de formação permanente (inicial no caso dos acadêmicos, continuada no caso das pesquisadoras). O processo formativo se deu por meio de planejamento participativo de sessões diagnósticas e de estudo, discussão e reflexão de textos de forma dialógica, nos quais os participantes relataram suas vivências no que diz respeito ao processo de educação sexual recebida e ao processo de formação inicial na graduação, explicitando concepções e mudanças conceituais a respeito da temática da sexualidade.

A análise e a discussão dos dados têm como referencial teórico a análise do discurso desenvolvida por Foucault (1999) e a proposta de Schön (1992) para a formação de profissionais reflexivos, na qual o autor propõe níveis diferentes de reflexão sobre a prática. Segundo Schön, na ação docente se manifesta um saber-fazer que também pode ser chamado de conhecimento tácito, intuitivo, espontâneo, experimental, cotidiano. Na prática docente e de outros profissionais reflexivos se manifesta também uma reflexão-na-ação, na qual o profissional se deixa surpreender por um 
problema inesperado, reflete sobre este fato e procura compreender a razão por que foi surpreendido, reformula o problema suscitado pela situação e efetua uma experiência onde testa uma hipótese levantada. "Este modo de reflexão-na-ação não exige palavras. Por outro lado, é possivel olhar retrospectivamente e refletir sobre a ação e sobre a reflexãona-ação. Esta é uma ação, uma observação e uma descrição, que exige o uso de palavras" (SCHÖN, 1992, p. 77-91).

Uma dimensão da reflexão-na-ação é o que aquele pesquisador chama de "emoções cognitivas" e que tem a ver com confusão e incerteza e "[...] um professor reflexivo tem a tarefa de encorajar e reconhecer, e mesmo de dar valor à confusão dos seus alunos. Mas também faz parte das suas incumbências encorajar e dar valor à sua própria confusão" (SCHÖN, 1992, p. 77- 91). A reflexão-na-ação se manifesta também na interação interpessoal que se estabelece na ação, entre professor e um aluno ou um grupo de alunos, entre professores e pais, entre educadores e entre atores de uma instituição ou interinstitucionalmente. Nestas, o profissional se depara com problemas que precisam ser re-pensados, pensados sob uma nova perspectiva ou que necessitam de uma reflexão sobre a reflexão-na-ação. Este trabalho tem como objetivo realizar este tipo de reflexão mais aprofundada de dados da ação e da reflexão-na-ação, considerados relevantes após a realização da investigação-formação.

Assim, apresentamos na próxima seção, uma descrição da ação (dois encontros de investigação-formação) com destaque para as reflexões ocorridas ao longo do processo.

\section{A INVESTIGAÇÃO-FORMAÇÃO OU PESQUISA-AÇÃO COLABORATIVA}

Dos onze acadêmicos de Licenciatura em Ciências Biológicas (C) que participaram dos dois encontros, oito eram mulheres ainda jovens, entre dezoito e vinte e cinco anos; quanto ao estado civil, cinco se declararam solteiras, uma casada, uma em "união estável" e uma respondeu "outros". Apenas duas colaboradoras disseram ser mãe. Três colaboradores eram jovens solteiros, com idade entre 20 e 23 anos, sem filhos. Os colaboradores 
cursavam níveis diferentes da graduação, sendo que dois homens e duas mulheres estavam em fase final ( $8^{\circ}$ período) enquanto os demais estavam no meio do curso $\left(3^{\circ}, 4^{\circ}\right.$ e $6^{\circ}$ períodos).

Nos encontros entre a pesquisadora e os acadêmicos colaboradores predominaram a reflexão dialógica, o estudo de textos, a troca de experiências, conforme recomendação de Ibiapina (2008) e passamos à descrição dos dois primeiros encontros realizados de forma colaborativa na pesquisa ora relatada, de forma descritiva e dando destaque para os diálogos ocorridos, nos quais se percebe todo um movimento reflexivo dos participantes durante e após a interação.

\subsection{Episódio 1: a entrada em campo}

O primeiro encontro de investigação-formação entre os colaboradores (C) e a pesquisadora (PI) aconteceu oficialmente no dia 13 de outubro de 2016 à tarde e teve como objetivo: apresentar a proposta de pesquisa, levantar o perfil e as expectativas dos colaboradores. Sobre essa primeira fase Pereira esclarece que se trata de "[...] aclarar e diagnosticar uma situação prática ou um problema prático que se quer melhorar ou resolver" (1998, p.162). Este teve duração de duas horas e participaram 10 (dez) colaboradores, no qual responderam um questionário com 12 (doze) questões que diagnosticou o perfil dos colaboradores e alguns dados sobre seus processos de formação, bem como suas expectativas como ponto de partida para os próximos encontros. Enquanto preenchiam as questões eles comentavam entre si:

- "Nós estudamos isso na faculdade" e outro aluno comentou:

- "Eu devo ter faltado a essa aula, pois não estudei nada sobre esse assunto".

Havia três alunos que cochichavam e riam demonstrando pudor e timidez quanto ao tema. Uma aluna comentou:

- "Nossa eu nem tinha pensado em todos esses assuntos dentro dessa temática!". Outra disse: - "Eu nem tinha pensado nesse assunto: se eu me sinto preparada para trabalhá-lo!". 
Estes diálogos mostram que eles já refletiam quanto à sua formação enquanto educadores sexuais, com alguns evidenciando que não se sentiam ainda preparados para discussões sobre o assunto, pois enquanto preenchiam as respostas surgiam comentários como:

- "Nossa, mas eu sabia isso e agora esqueci"; - "Eu já vi alguma coisa sobre isso, mas agora não lembro"; - "Difícil isso, hein?".

Pelas respostas dadas verifica-se que alguns alunos do $6^{\circ}$ e $8^{\circ}(\mathrm{C} 2$; $\mathrm{C} 3$; C4; C8; C10) receberam orientações para trabalharem em forma de palestra, oficina e minicurso nos projetos do PIBID e também estudaram alguns temas dentro das disciplinas, mas todos são unânimes em afirmar que ainda não se sentem preparados para esta tarefa; um/a colaborador se diz "aberto" para realizá-la e outro/a se acha psicologicamente preparado/a, mas admite que sente falta de maiores conhecimentos sobre o tema. $O$ questionário também buscou identificar o que mais marcou os participantes no que diz respeito à sexualidade humana durante sua trajetória de vida e formação. As respostas evidenciam a predominância do discurso em torno do preconceito em relação à homossexualidade e da diversidade de gênero, com a qual entraram em contato, especialmente após ingresso no ensino superior. Outros colaboradores se referem às "curiosidades e dúvidas dos alunos" (C8) e ao "despreparo psicológico dos alunos, por verem tudo em poucas aulas e de modo direto" (C4), referindo-se ambos às aulas de ciências em que se estuda a reprodução sexuada.

Dois dos colaboradores se referem a experiências pedagógicas marcantes: uma foi sobre prevenção de doenças sexualmente transmissíveis (DST) e de gravidez precoce: "no último ciclo do ensino fundamental foi realizado palestra sobre sexualidade, frisando DST, gravidez precoce e métodos contraceptivos e no final foi dado um pintinho para cada aluno [que eles teriam que cuidar], simulando uma gravidez precoce. Foi uma experiência incrível" (C7). Outro respondeu que "o que mais me marcou foi a realização de um minicurso que ajudei a ministrar com estudantes do ensino médio" (C3). 
Outra questão tratava do levantamento das concepções dos colaboradores sobre sexo e sexualidade e as discussões e diálogos sobre estes conceitos serão apresentadas no próximo episódio (Seção 3.2).

\subsection{Episódio 2: Enfim, começamos a interagir mais naturalmente}

O segundo encontro aconteceu no dia 19 de outubro de 2016 à tarde e contou com a participação de mais uma colaboradora que compareceu e pediu para ser inserida na pesquisa. O que chamou a atenção da pesquisadora ao fazer o registro ampliado do encontro anterior foi a falta de interação entre os participantes, o que foi atribuído ao procedimento metodológico utilizado (formalização de pesquisa com aplicação de questionário). A pesquisadora registrou sua percepção:

Eu senti que esse encontro demorou uma eternidade; eu não estava tão confortável e também não estava satisfeita com o planejamento para o segundo encontro, pois havia planejado pedir aos colaboradores para fazerem um memorial durante a pesquisa para registrar concepções, emoções, aprendizagens, mas eu também buscava interação e diálogo entre nós (Registro Ampliado por PI).

Ao conversar por telefone com a orientadora, esta desencadeou uma reflexão com o seguinte questionamento: "por que você vai propor o memorial?"; "o que você pretende nesse encontro?"; "como foi o encontro anterior?". Essa reflexão levou à reformulação dos planejamentos da pesquisa (descartando-se a ideia do memorial) e do segundo encontro, no qual decidimos fazer o feedback das respostas dos alunos ao questionário, analisando com eles as respostas, proporcionando um diálogo acerca das concepções iniciais diagnosticadas sobre a temática investigada. Uma síntese das respostas foi apresentada em datashow. No feedback das concepções dos participantes sobre a temática, focamos na terminologia "sexo" e "sexualidade"i, que são conceitos fundamentais para um início de reflexão e formação nesta área.

Percebi que essa proposta agradou aos participantes que começaram a se entreolhar e dar risadas, uma participante disse que sentiu vergonha de escrever errado, outro disse que sentiu medo. Eles revelaram que não se sentiram tão à vontade em responder o questionário. Agora com a nova metodologia senti que 
foi bem aceita a ideia de visualizarem seus dados e então iniciamos a apresentação em slides (Registro Ampliado de PI).

De forma bem mais descontraída, cada um foi lendo suas respostas e interagindo, o que fica evidenciado no diálogo que se segue:

- "Não recebi formação, apenas participei de palestras que aconteciam na escola, mesmo com essas palestras sempre, não havia esclarecimento sobre a sexualidade" e continuou dizendo: "às vezes recebemos formação muito pontual, sobre DST, mas tem outras coisas que precisamos estudar.". Outro colaborador leu sua resposta e completou:

- "Nós fizemos uma oficina sobre métodos contraceptivos, doenças, mas não recebemos formação para isso, não houve formação, recebemos algumas informações.". Ao serem questionados sobre a formação deles dentro do currículo formal, uma aluna disse: - "Em embriologia estudamos algo, mas é mais dentro da área da biologia, eu não recebi formação, apenas algumas informações; a sexualidade é além de informação, tem coisas que eu não sei como lidar".

Outra reposta foi lida e comentada: - "Ainda não me sinto preparado/a. Embora já tenha lido vários textos sobre o assunto, falta uma conversa com alguém que realmente entenda do assunto". Ao ser questionado sobre quem seria "esse alguém" C3 respondeu: "alguém que não deixe transparecer opiniões, mas que diga o porquê é errado...". Uma aluna relatou sobre um filme que assistiu onde os pais pegam um menino se masturbando e batem no adolescente, falam que é errado, mas não explicam o porquê é errado. Então, o diálogo adentra para o tabu relacionado com a masturbação, com PI dizendo que "cientificamente, essa é uma ação que faz parte da vida do ser humano; que nem todos praticam; que não vai nascer pelos nas mãos; provocar câncer; viciar ou provocar a loucura.". Falou-se sobre a importância da orientação sobre isso, sobre respeito ao próximo e privacidade. Um/a aluno/a falou que a masturbação feminina ainda é um tabu, que não se fala sobre isso, que no Brasil existem muitos preconceitos e que isso é cultural. 
Diante do comentário da pesquisadora sobre a importância do PIBID na formação docente desses acadêmicos enquanto educadores sexuais, a colaboradora que se integrou ao grupo neste segundo encontro afirmou que ela estudou esse tema para apresentar palestras nas escolas, pois, segundo ela, "a escola não quer falar sobre esse assunto por medo dos pais, então pede para os bolsistas do PIBID realizarem essa ação". Então, realizouse uma reflexão: a escola tem medo dos pais ou não se sente capacitada para isso? C7 respondeu que a escola não tem formação para discutir esses assuntos, mas que muitos pais também não querem que a escola fale sobre o mesmo. C6 lembrou que a maioria dos pais também não teve formação para isso, então eles não falam com os filhos. Ele/aa ainda afirmou que a religião faz com que os pais não discutam isso com os filhos, que sexo é um tabu e muitos acham que se falarem sobre esse assunto estimularão os filhos a praticarem sexo (grifo nosso). Então C2 disse:

- "Quando eu era mais nova, minha melhor amiga era uma lésbica e minha mãe perguntava se eu não ia pegar 'a doença' da minha colega, ela achava que eu fosse me transformar numa lésbica. Muitos me falavam como eu podia andar com aquela menina..., as pessoas têm um medo, um preconceito... diziam para ela que ela era bonita, que a fase ia passar, mas minha amiga dizia que não". A aluna prosseguiu dizendo: "eu falava para a minha mãe: 'eu prefiro andar com ela que não é falsa' e um monte de coisa. Todos me criticavam; eu falava para meu irmão que ele ia ter filhos e eles podiam nascer gays, ele falava: 'dou um pau!'; e eu falava 'você prefere que ele seja bandido?'. Ele falava 'ahh, prefiro, prefiro!'”.

No momento dessa fala dois colaboradores se olharam com desaprovação, balançaram a cabeça negativamente desaprovando a fala da participante, então um deles se pronunciou:

- "Mencionar que prefere ter um filho bandido que um gay... Gente, porque tem que comparar gay a bandido e pessoas falsas? De certa forma isso é um preconceito disfarçado, acaba comparando a gente à coisa ruim.". Com essa fala o colaborador se declara homossexual e fica insatisfeito com a colocação da colega. O outro colaborador fala: "não tem nada a ver, 
ficar comparando com bandido, tem que comparar com outra pessoa qualquer, não com bandido!".

Como o clima ficou tenso entre os colaboradores, PI interveio ponderando que "de tanto ela ouvir isso, acaba por reproduzir essa fala, mas que a ação dela não é preconceituosa". A aluna concordou dizendo que sempre ouviu esse tipo de comentários no seu ambiente.

O diálogo prosseguiu com C7 afirmando: "O que está pegando no momento é a falta de conhecimento de muitos sobre o assunto.". C6 afirmou: "eu já presenciei muita fala preconceituosa quanto à questão do gênero e o mais difícil é quando vem de alguém que tem instrução e devia dar o exemplo. A gente não sabe como lidar.". A este respeito, C5 comentou que em sua sala de aula um aluno perguntou ao professor a diferença entre homo, hetero e trans e o docente disse que "existe homo e hetero, o resto é gambiarra". Eles riram da situação e disserem que o professor ficou perturbado e se enganou na afirmação que fez, pois, na realidade ele quis dizer que existe homem e mulher e o resto era "gambiarra.".

Esse momento de diálogo foi avaliado pela pesquisadora como "produtivo", pois, enquanto os alunos debatiam os assuntos e os fatos que marcaram sua trajetória enquanto alunos e professores surgiram casos que não foram colocados no questionário, com a pesquisadora iniciante atuando como mediadora, especialmente nos momentos mais tensos e conflituosos. A seguir, realizou-se um debate sobre os conceitos de sexo e sexualidade, a partir do que eles escreveram no questionário. Eis que C3 falou: "é difícil para a gente saber falar a diferença entre esses dois termos, pois associamos sexo à sexualidade" e perguntou "sexo diz respeito ao masculino e feminino? Definir com palavras é difícil". C10 tem a mesma concepção de C3: "Na verdade sexo se refere a masculino e feminino." Então C6 ensaiou uma distinção: "Sexo eu entenderia como ato sexual, sexualidade é tudo que tange a diversidade de gênero..., não consigo definir". Então C3 disse: "Concordo com você, pois, no trabalho que apresentamos em um evento, colocamos sexo como masculino e feminino e 
a pessoa que estava coordenando o $\mathrm{GT}^{3}$ sugeriu gênero, por isso acredito que masculino e feminino é gênero.". C12 deu uma opinião tocando em um ponto polêmico: sobre homossexualismo ser uma opção ou existir uma orientação (biológica ou cultural) que a determina: "a sexualidade diz respeito à orientação, não é uma opção".

Como planejado, a pesquisadora projetou um vídeo em que a pesquisadora e professora da UNICAMP Guacira Lopes Louro ${ }^{4}$ fala sobre as formas da expressão de sexualidade humana, o papel da escola nesse processo e as teorias recentes nessa área de conhecimento. Ela diferencia os conceitos de sexo e sexualidade, apontando o papel dos códigos culturais na vivência da sexualidade; mostra como os estudos feministas e as minorias sexuais estão produzindo teoria para questionar o que se tem considerado "normal" em nossa cultura: que o sexo (macho ou fêmea) determina o gênero (feminino ou masculino). Assim, faz referência à teoria queer, que ela adota em seus estudos e faz outros apontamentos referentes à temática da sexualidade na escola e na formação de professores. No vídeo, a pesquisadora relacionou o conceito de sexualidade com as manifestações de prazer que permeiam a vida do individuo do nascimento até a morte, como por exemplo, a paquera, o primeiro beijo, a atração por outras pessoas, dizendo que isso está ligado à sexualidade.

Ao retomar o diálogo, após a exibição do vídeo, a pesquisadora (PI) que mediava o debate fez uma preleção sobre as fases do desenvolvimento da sexualidade, baseada na teoria freudiana e a importância de a criança vivenciar essas fases, superando os conflitos próprios de cada uma, pois muitos problemas sexuais do adulto teriam origem na forma como a pessoa vivencia as fases oral, anal e fálica antes de atingir a fase genital, a partir da adolescência, como aponta a Psicanálise.

\footnotetext{
3 O aluno se referiu ao Grupo de Trabalho em que apresentou uma comunicação oral no SEMIEDU: Seminário Educação 2016 - Saberes e identidade, povos, culturas e educações. Universidade Federal de Mato Grosso.

${ }^{4}$ LOURO, G. L. Gênero e sexualidade na escola - Parte 3. Programa Nós da Educação. TV Paulo Freire. $2008 . \quad$ Disponível em http://www.gestaoescolar.diaadia.pr.gov.br/modules/video/showVideo.php? video=12766. Acessado em 15/09/2016.
} 
Os colaboradores iniciaram uma discussão sobre a dificuldade que eles têm em conceituar os termos sobre gênero, o que já tinha sido manifestado na pergunta feita em sala para um professor da turma e a pesquisadora deixou que falassem de suas dúvidas, pois esse tema seria abordado num encontro futuro.

Os colaboradores trouxeram várias falas sobre suas vivências relacionadas com as regras sociais que vão diferenciando homens e mulheres, o masculino do feminino em sua cultura. Uma aluna afirmou que quando criança era proibida de brincar com primos meninos, que ela sendo menina só podia brincar com meninas e os meninos com meninos; que os avós proibiam, mas não falavam por quê. Ela afirmou que hoje não consegue dar um abraço em seus primos, que não se sente confortável, ela reforça sobre a construção social das regras, sobre o que é permitido e o que é proibido para mulheres e homens. Ainda falando sobre gênero, C3 falou sobre os banheiros públicos que são masculinos e femininos, mas nos aviões e ônibus é totalmente normal todos utilizarem o mesmo banheiro. C2 disse que foi na igreja de uma tia e que lá os homens sentam do lado direito e as mulheres do lado esquerdo; que as mulheres usam o véu, pois se elas não estiverem usando o véu não estão no mesmo nível que os homens. C3 então disse: - "Eu pensava que o véu significava outra coisa relacionada à religiosidade, mas descobri estudando que realmente o véu está relacionado à submissão da mulher; que se as mulheres não usarem o véu Deus não as vê.". C2 acrescentou: - "Só sei que lá as mulheres precisam do véu. Eu ganhei um dela e quando o usava eu achava que eu tinha um poder maior com Deus, depois eu cresci..., nossa..." (ela ri) e percebe-se que ela ficou envergonhada de assumir que tenha tido esta crença.

Neste diálogo, o discurso religioso entrou em cena e a pesquisadora refletiu sobre sua atitude naquele momento, quando fez o registro ampliado da videogravação deste encontro:

"Não falo nada sobre essa situação que eles comentam, pois não quero entrar num debate sobre religião neste momento. A emoção que 
experimentei foi de medo de tomar um posicionamento, então me calei." (Registro Ampliado de PI).

C6 falou: "Quando comecei a namorar eu fui para Vilhena e teoricamente, eu não era mais virgem. Nossa..., eu nunca vou esquecer a fala da minha avó, que eu era uma perdida". Disse ainda que questionava a família sobre isso. Nesse momento, a pesquisadora emocionou-se ao compartilhar sua experiência pessoal a respeito: "Por eu casar grávida vivi momentos de humilhação na família, mas consegui superar tudo isso, embora tenha machucado". Continuando esse assunto C6 falou que seus pais falavam que se ela ficasse namorando seria uma perdida e ninguém ia querer casar com ela e novamente a pesquisadora compartilha sua experiência, abordando sobre as orientações de seus pais, que diziam que devia se guardar para um homem só, referindo-se ao que se tem chamado de tabu da virgindade, considerado superado nos grandes centros urbanos ocidentais, a partir da revolução sexual ocorrida nas últimas décadas do século XX, mas percebe-se que na cultura local ainda é muito forte o valor que se dá à virgindade antes do casamento. A pesquisadora registrou que "acabamos nos identificando nas histórias uns dos outros", inseridas que estavam em um mesmo ambiente sócio-histórico-cultural.

A propósito, o diálogo abriu espaço para este compartilhar de experiências, não por acaso, pois o referencial teórico-metodológico da pesquisa estimula o uso de narrativas autobiográficas na pesquisa e na formação de professores. Para lbiapina "É por meio das narrativas de histórias de vida que os professores desvelam elementos que compõem o pensar e agir profissional, criando bases para a compreensão da própria profissão docente" (2008, p. 85). "Nesse processo, a compreensão dos professores sobre o seu trabalho é susceptível de influenciar as escolhas realizadas pelo pesquisador no decorrer do desenvolvimento da pesquisa, e vice-versa" (IBIAPINA, 2008, p. 20). Nesse processo o que temos é que os diversos pontos de vista e opiniões determinam o resultado final da pesquisa e promovem o desenvolvimento profissional e pessoal dos envolvidos. 
Para fechar o entendimento da definição de sexo e sexualidade, foi realizada a leitura de um texto (OLIVEIRA, 2010) que enfatiza que Sexo e Sexualidade são conceitos distintos: Sexo é o conjunto de características anatômicas e fisiológicas, o órgão sexual com o qual o indivíduo nasce e que a Sexualidade é a própria vida, num processo que vai do nascer ao morrer, envolvendo, além do nosso corpo, nossa história, nossos costumes, nossas relações afetivas, nossa cultura. Também foi lida uma definição da Organização Mundial de Saúde que considera a sexualidade humana parte integrante da responsabilidade de cada um; que não é sinônimo de coito e não se limita à presença ou não do orgasmo. É energia que motiva a encontrar o afeto, contato e intimidade e se expressa na forma de sentir, nos movimentos das pessoas e como estas se tocam e são tocadas (BRASIL, 1998; BOLETIM, 2000).

Na próxima seção realizamos a "reflexão sobre a ação e sobre a reflexão-na-ação" (SCHÖN, 1992), ampliando a discussão iniciada na Seção 3, a respeito dos conceitos de Sexo, Sexualidade e Educação Sexual.

\section{SEXO E SEXUALIDADE: TABU, POLÊMICA OU CONCEITOS POLISSÊMICOS?}

A palavra tabu foi usada várias vezes nestes dois encontros e sentimos a necessidade de ampliar a compreensão sobre a mesma, o que nos levou ao significado de outros dois conceitos: polêmica e polissemia.

O dicionário Aurélio 5 traz os significados que tabu pode adquirir: 1) "Proibição de determinada ação, de aproximação ou contato com algo ou alguém que é considerado sagrado. 2) Lugar, animal, objeto, coisa ou ação proibidos por temor de castigo divino ou sobrenatural. 3) Medo ou proibição de origem religiosa, social ou cultural. 4) Assunto de que não se pode ou não se deve falar. 5) Que é proibido. 6) Que não se pode ou deve proferir ou de que não se pode ou não se deve falar.".

$\mathrm{Na}$ fala de colaboradores que destacamos na seção anterior, a palavra tabu foi relacionada com religião, mas, por esta definição, vemos

${ }_{5}^{5}$ Disponível em <https://www.dicionariodoaurelio.com/tabu>. Acesso em 03/06/2017. 
que um tabu pode surgir por proibições de outra ordem, como econômica ou política. Ele também se associa com o medo de castigo pela transgressão de uma proibição; ou ao se tocar em um assunto de que não se pode ou não se deve falar, que é proibido. E o medo foi uma das emoções cognitivas expressadas por colaboradores e pela pesquisadora (PI) em alguns momentos: "[...] a escola tem medo dos pais [...]"; "a escola não tem formação para discutir esses assuntos, mas muitos pais não querem que a escola fale sobre o mesmo"; "[...] a maioria dos pais também não teve formação para isso, então eles não falam com os filhos"; "a religião faz com que os pais não discutam isso com os filhos, que sexo é um tabu e muitos acham que se falarem sobre esse assunto estimularão os filhos a praticarem sexo"; ao realizar o registro ampliado, Pl também disse ter sentido medo, pois a relação do discurso sobre sexualidade, o papel da mulher, sua submissão, dentro de uma formação discursiva religiosa perturbou o grupo. Também se percebe uma emoção cognitiva de vergonha por parte da colaboradora, associada à comparação do discurso religioso com o científico, feito por outro/a colega, no qual o científico é claramente colocado como conhecimento superior comparado com as crenças, mitos, superstições ou tabus atribuídos ao conhecimento religioso: "Eu pensava que o véu significava outra coisa relacionada à religiosidade, mas descobri estudando que realmente o véu está relacionado à submissão da mulher [...]"; "Só sei que lá as mulheres precisam do véu. Eu ganhei um dela e quando o usava eu achava que eu tinha um poder maior com Deus, depois eu cresci..., nossa...".

Pelas reações dos colaboradores e da pesquisadora, vemos como este tema ainda é tabu na cultura dos participantes da pesquisa, pois vem associado com interdição, medo, vergonha, humilhação. De tabu, sexo, sexualidade e educação sexual podem se transformar em silenciamentos ou em polêmicas. Tomando-se emprestada a definição' de polêmica disponível em dicionários on line e os significados que ela pode receber pelo contexto

${ }^{6}$ Disponível em <https://www.dicio.com.br/polemica-2/>. Acesso em 03/06/2017. 
linguístico em que for empregada: discussão, controvérsia sobre questões políticas, literárias, científicas, religiosas; altercação, contenda, controvérsia, debate, discussão, litígio.

Um tabu pode se transformar em uma polêmica, na qual um discurso pode se tornar hegemônico sobre outros, acarretando o silenciamento de outras formas de dizer, pensar, viver. Uma polêmica geralmente contém conceitos polissêmicos e falácias, utilizadas de forma inconsciente ou deliberada para enganar os oponentes e fazer prevalecer um tipo de discurso, conforme a definição de falácia7: "discurso falso que se passa por verdadeiro; engano. Modo errado de se conceber alguma coisa; erro"; "Qualidade do que é falaz, capaz de enganar; ilusão [...]"; "Todo enunciado ou raciocínio de teor falso, mas que se tenta passar por verdadeiro; sofismo".

Os PCN (BRASIL, 1998) também trazem definições da Organização Mundial de Saúde (OMS) que considera a sexualidade humana parte integrante da vida de cada um e inclui esta temática entre os direitos humanos, relacionada com a saúde. Segundo esta organização, a sexualidade influencia pensamentos, sentimentos, ações e interações e afeta tanto a saúde física como a mental; a sexualidade não é sinônimo de coito e não se limita à presença ou não do orgasmo. É energia que motiva a encontrar o afeto, contato e intimidade, e se expressa na forma de sentir, nos movimentos das pessoas e como estas se tocam e são tocadas. A sexualidade é uma temática que está intrínseca na vida e na saúde de todo e qualquer ser humano e vem assinalada por anseios e emoções que perpassam as relações pessoais e interpessoais, além de se fazer presente em todas as etapas do desenvolvimento do ser humano.

Ao refletir sobre os primeiros encontros realizados e sobre as reflexões que surgiram nas ações desenvolvidas nos mesmos, comparando os conceitos de sexo e sexualidade com outro autor que é referência nesta área (FOUCAULT, 1999), vimos que podemos relativizar essas definições e que os mesmos são conceitos polissêmicos (possuem vários significados e podem

\footnotetext{
${ }^{7}$ Disponível em <https://www.dicio.com.br/falacia/>. Acesso em 05/06/2017.
} 
assumir vários sentidos), ao contrário do que concluímos quando os definimos muito bem, baseados nos textos que consultamos naquele momento: entendíamos que Sexo e Sexualidade são conceitos distintos e bem definidos, como convém ao discurso científico, como já se registrou: "Esta distinção clara agradou aos colaboradores que até elogiaram a citação dizendo que "ela é muito boa, explica muito bem os conceitos'." (Registro Ampliado por PI). Entretanto, quando fizemos a leitura de Foucault (1999) que trata da história da sexualidade, encontramos uma posição diferente e inusitada, que nos levou a uma relativização destes conceitos, até então apresentados como "naturais", algo inato. Foucault (1999, p. 16) nos levou a desnaturalizar sexo e sexualidade, a olhar para estes termos dentro do "fato discursivo global", isto é, ele nos convida a colocar o sexo em discurso. Para este autor, isto significa "determinar em seu funcionamento e em suas razões de ser, o regime de poder-saber-prazer que sustenta, entre nós, o discurso sobre a sexualidade humana.". Na prática, ao se falar de sexo, é preciso perguntar: "Quem fala? Quais os lugares e os pontos de vista de que se fala? Que instituições incitam a fazê-lo? Quem armazena o conhecimento e difunde o que dele se diz?".

Após fazer cuidadoso estudo sobre a história da sexualidade, Foucault (1999) define sexualidade como uma ciência (scientia sexualis), um discurso sobre o sexo que se pretende "ser verdadeiro":

[...] nossa sociedade constituiu uma scientia sexualis. Mais precisamente, atribuiu-se a tarefa de produzir discursos verdadeiros sobre o sexo, e isto tentando ajustar, não sem dificuldade, o antigo procedimento da confissão às regras do discurso científico. A scientia sexualis desenvolvida a partir do século XIX, paradoxalmente, guarda como núcleo o singular rito da confissão obrigatória e exaustiva, que constituiu, no Ocidente cristão, a primeira técnica para produzir a verdade sobre o sexo. Desde o século XVI, esse rito fora, pouco a pouco desvinculado do sacramento da penitência e, por intermédio da condução das almas e da direção espiritual [...] emigrou para a pedagogia, para as relações entre adultos e crianças, para as relações familiares, a medicina e a psiquiatria. Em todo caso, há quase cento e cinquenta anos, um complexo dispositivo foi instaurado para produzir discursos verdadeiros sobre o sexo: um dispositivo que abarca amplamente a história, pois vincula a velha injunção da confissão nos métodos da escuta clínica. E através deste dispositivo, pôde aparecer algo como "sexualidade" enquanto verdade do sexo e de seus prazeres (FOUCAULT, 1999, p. 66-67).

Revista Exitus, Santarém/PA, Vol. 8, № 2, p. 273 - 299, MAl/AGO 2018. 
Ao considerar a sexualidade como scientia sexualis Foucault questionou também o conceito de sexo, visto como um "elemento do real" ou o "sexo em geral" e se perguntou:

"'O sexo' seria, na realidade, o ponto de fixação que apoia as manifestações 'da sexualidade' ou, ao contrário, uma ideia complexa historicamente formada no seio do dispositivo da sexualidade?" (FOUCAULT, 1999, p. 143).

Com este questionamento o autor não está negando a existência "[...] do 'sexo-natureza' (elemento do sistema do ser vivo, objeto para uma abordagem biológica)", mas chamando a atenção para o "sexo-história", "sexo significação" ou "sexo-discurso": uma derivação do dispositivo da sexualidade, construído ao longo dos últimos séculos na sociedade ocidental, que vem colocando a nós mesmos, por inteiro, sob o "signo do sexo", pois, para este autor, a velha questão filosófica "o que somos?" passou a ser colocada nos últimos séculos, "sob o signo do sexo":

[...] O Ocidente conseguiu, [...] colocar-nos, inteiros - nós, nosso corpo, nossa alma, nossa individualidade, nossa história - sob o signo de uma lógica da concupiscência e do desejo. Uma vez que se trata de saber quem somos nós, é ela, doravante, que nos serve de chave universal (FOUCAULT, 1999, p. 76).

Utilizando um método de análise do discurso com quatro regras básicas, em que se articulam poder e saber, defende a concepção de "[...] discurso como uma série de segmentos descontínuos, cuja função tática não é uniforme nem estável" (p. 95).

Mais precisamente, não se deve imaginar um mundo do discurso dividido entre o discurso admitido e o discurso excluído, ou entre o discurso dominante e o dominado; mas, ao contrário, como uma multiplicidade de elementos discursivos que podem entrar em estratégias diferentes. É essa distribuição que é preciso recompor, com o que se admite em coisas ditas e ocultas, em enunciações exigidas e interditas; como o que supõe de variantes e de efeitos diferentes segundo quem fala, sua posição de poder, o contexto institucional em que se encontra; com o que comporta de deslocamentos e de reutilizações de fórmulas idênticas para objetivos opostos. Os discursos como os silêncios (grifo nosso), nem são submetidos de uma vez por todas ao poder, nem opostos a ele. É preciso admitir um jogo complexo e instável em que o discurso pode ser, ao mesmo tempo, instrumento e efeito de poder, e também 
obstáculo, escora, ponto de resistência e ponto de partida de uma estratégia oposta. O discurso veicula e produz poder; reforça-o, mas também o mina, expõe, debilita e permite barrá-lo. Da mesma forma, o silêncio e o segredo dão guarida ao poder, fixam suas interdições; mas, também, afrouxam seus laços e dão margem a tolerâncias mais ou menos obscuras (FOUCAULT, 1999, p. 95-96).

Os discursos passam a ser vistos, então, segundo este autor, como "elementos ou blocos táticos no campo das correlações de força; podem existir discursos diferentes e mesmo contraditórios dentro de uma mesma estratégia [...]", mas, ao contrário, podem "[...] circular sem mudar de forma entre estratégias opostas" (p. 97).

A partir das quatro regras de análise do discurso, Foucault analisa quatro grandes linhas através das quais se desenvolveu o "dispositivo da sexualidade", a partir do século XVIII, ou melhor, "quatro grandes conjuntos estratégicos que desenvolveram dispositivos específicos de saber e poder a respeito do sexo". Estes não nasceram em bloco, mas assumiram coerência e atingiram "certa eficácia na ordem do poder e produtividade na ordem do saber, que permitem descrevê-los com relativa autonomia" (p. 99).

Na preocupação com o sexo, que aumenta ao longo do século XIX, quatro figuras se esboçam como objetos privilegiados de saber, alvos e pontos de fixação dos empreendimentos do saber: a mulher histérica, a criança masturbadora, o casal malthusiano, o adulto perverso, cada uma correlativa de uma dessas estratégias que, de formas diversas, percorreram e utilizaram o sexo das crianças, das mulheres e dos homens (FOUCAULT, 1999, p. 100) (grifo nosso).

\section{Assim, para Foulcault, a sexualidade (ou seja, o conhecimento}

científico sobre o sexo), na verdade, é o nome dado a um:

[...] dispositivo histórico: não à realidade subterrânea que se apreende com dificuldade, mas à grande rede da superfície em que a estimulação dos corpos, a intensificação dos prazeres, a incitação ao discurso, a formação dos conhecimentos, o reforço dos controles e das resistências, encadeiam-se uns aos outros, segundo algumas grandes estratégias de saber e de poder (FOUCAULT, 1999, p. 100).

Esse dispositivo veio se superpor nas sociedades ocidentais modernas ao dispositivo da aliança, que pode ser identificado em todas as sociedades (sistema de matrimônios, de fixação e desenvolvimento dos parentescos, de transmissão dos nomes e dos bens). O dispositivo da sexualidade também se 
articula aos parceiros sexuais, mas de modo muito diferente do dispositivo da aliança:

\begin{abstract}
O dispositivo da aliança se articula em torno de um sistema de regras que define o permitido e o proibido, o prescrito e o ilícito; o dispositivo de sexualidade funciona de acordo com técnicas móveis, polimorfas e conjunturais de poder. O dispositivo da aliança conta, entre seus objetivos principais, o de reproduzir a trama de relações e manter a lei que as rege; o dispositivo de sexualidade engendra, em troca, uma extensão permanente dos domínios e das formas de controle. Para o primeiro, o que é pertinente é o vínculo entre parceiros com status definido; para o segundo, são as sensações do corpo, a qualidade dos prazeres, a natureza das impressões, por tênues e imperceptíveis que sejam. Enfim, se o dispositivo da aliança se articula fortemente com a economia devido ao papel que pode desempenhar na transmissão e circulação das riquezas, o dispositivo da sexualidade se liga à economia através de articulações numerosas e sutis, sendo o corpo, a principal - corpo que produz e consome. Numa palavra, o dispositivo da aliança está ordenado por uma homeostase do corpo social, a qual é sua função manter, daí seu vínculo privilegiado com o direito; daí também, o fato de o momento decisivo, para ele, ser a "reprodução". O dispositivo da sexualidade tem, como razão de ser, não o reproduzir, mas o proliferar, inovar, anexar, inventar, penetrar nos corpos de maneira cada vez mais detalhada e controlar as populações de modo cada vez mais global (FOUCAULT, 1999, p. 101) (grifo nosso).
\end{abstract}

Ao relativizar os conceitos de sexo e sexualidade com auxilio da análise do discurso, vemos quão complexa é a tarefa de formar professores para atuarem como educadores sexuais, em um contexto em que os discursos sobre sexo e sexualidade se multiplicam e invadem as instituições familiares e escolares através da revolução tecnológica provocada pelas mídias, especialmente a Internet, fazendo girar a roda da política, da economia, do mercado, onde os corpos são objeto de consumo e ao mesmo tempo são consumidos (propagandas de estilos de vida, prostituição masculina e feminina, tráfico humano, pedofilia, abusos sexuais, tratamentos psiquiátricos e psicológicos, exames, consultas, medicamentos etc.).

Além das várias dúvidas, silêncios e discordâncias apresentadas nos diálogos, diante do questionamento sobre terem recebido formação e se se sentem preparados para atuarem como educadores sexuais na prática docente na educação básica, os colaboradores (C) deram algumas respostas que expressam a necessidade de formação permanente diante da complexidade da questão, pressentida mesmo sem um aprofundamento 
teórico como o que ensejamos fazer neste trabalho. Um grupo disse que não recebeu formação para ser um/a educador/a sexual na educação básica: - "Não recebi formação, apenas participei de palestras que aconteciam na escola. Mesmo com essas palestras sempre, não havia esclarecimento sobre a sexualidade. Não estou preparada, tenho muitas dúvidas sobre o assunto" (C1); "Creio que preciso de mais conhecimento na área, pois todo conhecimento adquirido é pouco" (C5); "[...] fomos orientados, mas foi em nível de informação. Não me sinto preparada" (C6); "Não. Não me sinto preparado, mas aceitaria o desafio, pois penso que no decorrer de experiências vou me preparando" (C9).

Mesmo os que disseram ter recebido formação, esta percepção também existe, sem dúvida:

- "Sim [recebi formação]. Totalmente preparada não, pois acredito que ainda preciso de mais preparo, mais estudo, mais informação" (C2); "Sim, porém, esporadicamente. Não me sinto totalmente preparado, mas a formação é algo constante e permanente apesar disso, me considero aberto para abordar o assunto" (C3); "Sobre o conteúdo ainda é preciso estudar e rever alguns conceitos. Quanto à questão psicológica sinto-me apta pra trabalhar tais assuntos" (C7); "Nas disciplinas de Metodologia do Ensino de Ciências I, Metodologia de Biologia II e Bioética aconteceram estudos e discussões sobre esse tema. Não totalmente, mas procuro me informar e conhecer mais sobre o assunto" (C10); "Dentro do PIBID os bolsistas já trabalharam essa temática nas escolas [...]. Embora já tenha lido vários textos sobre o assunto, falta uma conversa com alguém que realmente entenda do assunto" (C8).

Esta última fala remete para a importância de se trabalhar também com os formadores de professores, pois tanto pais, como professores e seus formadores, líderes religiosos, políticos etc., estão sendo atravessados pela multiplicidade de discursos articulados no dispositivo da sexualidade e geralmente se sentem impotentes diante das rápidas transformações ocorridas no campo dos costumes e valores. Ao mesmo tempo, estes agentes sociais sentem a responsabilidade na construção de valores 
morais elevados e a necessidade de proteção das crianças e adolescentes que estão sob seus cuidados, por estes serem mais suscetíveis de influências de agentes aliciadores, abusadores, exploradores, mercantilistas: a infinidade de formas de "antiescola" a que Bruner se refere em um de seus trabalhos sobre educação (2001, p. 42).

Ao finalizar esse artigo, acreditamos como Thiollent e Colette (2014), que experiências de pesquisa-ação colaborativa como esta são boas estratégias em torno desta importante questão de formação de professores para atuarem como educadores sexuais na educação básica, nos lares, nas comunidades religiosas, bem como a formação de seus formadores. Nelas podemos formar subcomunidades de aprendizagem (em que seus membros se especializam em aprender) na qual $\circ$ professor (ou $\circ$ pesquisador) não se sinta onipotente e monopolizador das ações e reflexões, mas todos "constroem 'andaimes' uns para os outros", desenvolvem "a capacidade de julgar, tornem-se autoconfiantes e capazes de trabalhar bem uns com os outros." (BRUNER, 2001, p. 29-30). Nestas, "os membros do grupo devem se ajudar mutuamente a ver o estado da situação e aprender o macete da função" que deve ou está desempenhando no grupo, através de uma pedagogia interativa e intersubjetiva. Ao contrário do que dizem os críticos tradicionais, Bruner defende que essas subcomunidades de aprendizagem "não reduzem o papel do professor nem sua 'autoridade'. O que acontece é que o professor assume a função adicional de incentivar outros a compartilhá-la" (p. 30). Podemos dizer o mesmo do papel do pesquisador-formador experiente de universidades numa pesquisa-ação colaborativa com professores da educação básica.

\section{CONSIDERAÇÕES FINAIS}

Após realizar a "reflexão sobre a ação e sobre a reflexão-na-ação" podemos afirmar que nossa compreensão sobre os significados de sexo e sexualidade se aprofundou, indo além de definições claras propostas por 
alguns textos que foram utilizados na investigação-formação, permitindo entrever uma complexidade ainda maior que a imaginada no início deste trabalho (fase de elaboração do projeto de pesquisa), permeada por conhecimentos históricos, políticos, econômicos, muito além da visão científica (biologia, ciências sociais e humanas) e da moralidade.

Nesta investigação-formação, vimos os participantes socializarem suas histórias de vida e experiências vivenciadas no que diz respeito à educação sexual e pudemos perceber o grande trabalho mental envolvido no relato de suas vivências, pensando e refletindo sobre posturas, valores e comportamentos adotados, (re)significando, atribuindo novos significados aos acontecimentos vividos, reformulando sua capacidade de agir autonomamente (agência) e sua auto estima (BRUNER, 2001). Pois, o processo de reflexão inerente à pesquisa-ação é importante para a tomada de consciência dos envolvidos de muitos aspectos inconscientes ou subconscientes, de normas que nem sempre estão claras na cultura, nas instituições ou de experiências que são difíceis de serem simbolizados através da linguagem. Neste tipo de pesquisa, os pesquisadores influenciam, assim como são influenciados, por ser este um procedimento flexível, onde todos participam e colaboram democraticamente num processo permanente de transformação social e de desenvolvimento pessoal e profissional.

O registro ampliado realizado enquanto a pesquisadora assistia à videogravação dos encontros favoreceu uma tomada de consciência com certo distanciamento da prática, o que proporcionou a visualização das próprias ações e as dos outros (colaboradores): posturas e comportamentos dotados de intencionalidade, afetos e emoções durante as interações com os professores em formação e a tomada de consciência da necessidade de mudanças que se poderia ou se deveria fazer.

Não podemos ficar de braços cruzados enquanto vemos o dispositivo da sexualidade movimentando a economia global com cifras de bilhões de dólares. Uma explosão de informação, imagens, propagandas e outras mensagens sobre sexo e sexualidade bombardeiam nossos sentidos na cultura ocidental contemporânea, impregnando-nos de termos sem sentido, 
instigando curiosidade e vontade de saber, impondo valores novos e desestabilizando valores tradicionais.

A tarefa de "ensinar/aprender" fica ainda mais desafiadora neste contexto cultural em que uma multiplicidade de discursos se chocam, disputando validade, poder e espaço-tempo nas mídias, nos currículos escolares, em materiais didáticos, nas legislações, nas igrejas, na política e no mercado. Sim, no mercado, pois a economia é um dos principais elementos que se alimenta da nossa vontade de saber e tem o poder de produzir identidades, moldar corpos e mentes, alma e espírito, sempre travestido de "validade científica".

\section{REFERÊNCIAS}

BOLETIM Informativo DST/AIDS. Diretoria de epidemiologia e vigilância Sanitária; Diretoria executiva de epidemiologia, Programa Estadual DST/AIDS. Secretaria de Saúde - PE. Jan/Abr. 2000. Ano II, n. 1.

BRASIL. MEC / Secretaria de Educação Fundamental. Parâmetros Curriculares Nacionais. Terceiro e quarto ciclos do ensino fundamental / Temas Transversais. Brasília: MEC, 1998.

BRUNER, J. A cultura da educação. Porto Alegre: ARTMED, 2001.

FOUCAULT, M. (1988). A história da sexualidade I: A vontade de saber. 13 ed. Rio de Janeiro: Ed. Graal, 1999.

IBIAPINA, I. M. L. de M. Pesquisa colaborativa: investigação, formação e produção de conhecimentos. Brasília: Liber Livro Editora, 2008.

OLIVEIRA, V. de. A psicologia do desenvolvimento e o estudo científico da adolescência: aspectos biológicos, emocionais, sexuais, psicossociais e cognitivos da adolescência. Unidade 3, Eixo Pedagógico. In ROCHA, D. M. S. da (Coord.). Desenvolvimento e crescimento. Módulo IV do Curso de Licenciatura em Biologia na modalidade de Educação a Distância. Palmas: Universidade Federal do Tocantins, 2010.

PEREIRA, E. M. de A. Professor como pesquisador: o enfoque da pesquisaação na prática docente. In: FIORENTINI, D.; GERALDI, C. M. G.; PEREIRA, E. M. A. (Orgs.). Cartografias do trabalho docente: professor(a)-pesquisador(a). Campinas: Mercado de Letras, 1998.

ROCKWELL, E. Relatório técnico: Reflexiones sobre el proceso etnográfico (1982 - 1985). Depto. de Investigaciones Educativas / Centro de Investigación y de Estudios Avanzados, IPN: México, 1987. 
SCHÖN, D. Formar professores como profissionais reflexivos. In NÓVOA, A. Os professores e a sua formação. Lisboa / Portugal: Publicações Dom Quixote, 1992.

THIOllent, M. J. M.; COlETTE, M. M. Pesquisa-ação, formação de professores e diversidade. Acta Scientiarum. Human and Social Sciences (UEM), 2014, Vol. 36, no. 2, p. 207-17.

Recebido em: Julho de 2017 Aprovado em: Janeiro de 2018 